\title{
(2) OPEN ACCESS \\ Association between triage level and outcomes at Médecins Sans Frontières trauma hospital in Kunduz, Afghanistan, 2015
}

\author{
Hadjer Latif Daebes (D) ,' Linnea Latifa Tounsi, ${ }^{1}$ Maximilian Nerlander, ${ }^{1}$ \\ Martin Gerdin Wärnberg (D) ,1,2 Momer Jaweed, ${ }^{3}$ Bashir Ahmad Mamozai, ${ }^{3}$ \\ Masood Nasim, ${ }^{4}$ Miguel Trelles, ${ }^{5}$ Johan von Schreeb ${ }^{1}$
}

Handling editor Ellen J Weber

Additional supplemental material is published online only. To view, please visit the journal online (http://dx.doi. org/10.1136/emermed-2020209470)

${ }^{1}$ Center for Research on Health Care in Disasters, Department of Global Public Health, Karolinska Institutet, Stockholm, Sweden

${ }^{2}$ Function Perioperative Medicine and Intensive Care, Karolinska University Hospital, Solna, Sweden

${ }^{3}$ Medical Department, Médecins Sans Frontières, Kunduz, Afghanistan

${ }^{4}$ Medical Coordination, Médecins Sans Frontières, Kabul, Afghanistan

${ }^{5}$ Medical Department Operational Centre Brussels, Doctors without Borders, Bruxelles, Belgium

Hadjer Latif Daebes, Department of Public Health Sciences, Karolinska Institute, 17177 Stockholm, Sweden; hadjer.daebes@vgregion.se

Received 22 January 2020 Accepted 25 October 2021

\section{Correspondence to}

\section{ABSTRACT}

Background Five million people die annually due to injuries; an increasing part is due to armed conflict in low-income and middle-income countries, demanding resolute emergency trauma care. In Afghanistan, a lowincome country that has experienced conflict for over 35 years, conflict related trauma is a significant public health problem. To address this, the non-governmental organisation Médecins Sans Frontières (MSF) set up a trauma centre in Kunduz (Kunduz Trauma Centre (KTC)). MSF's standardised emergency operating procedures include the South African Triage Scale (SATS). To date, there are few studies that assess how triage levels correspond with outcome in low-resource conflict settings

Aim This study aims to assess to what extent SATS triage levels correlated to outcomes in terms of hospital admission, intensive care unit (ICU) admission and mortality for patients treated at KTC.

Method and materials This retrospective study used routinely collected data from KTC registries. A total of 17970 patients were included. The outcomes were hospital admission, ICU admission and mortality. The explanatory variable was triage level. Covariates including age, gender and delay to arrival were used. Logistic regression was used to study the correlation between triage level and outcomes.

Results Out of all patients seeking care, $28.7 \%$ were triaged as red or orange. The overall mortality was $0.6 \%$. In total, $90 \%$ of those that died and $79 \%$ of ICUadmitted patients were triaged as red.

Conclusion The risk of positive and negative outcomes correlated with triage level. None of the patients triaged as green died or were admitted to the ICU whereas $90 \%$ of patients who died were triaged as red.

\section{BACKGROUND}

C) Author(s) (or their employer(s)) 2021. Re-use permitted under CC BY-NC. No commercial re-use. See rights and permissions. Published by BMJ.

To cite: Daebes $\mathrm{HL}$,

Tounsi LL, Nerlander M, et al. Emerg Med J Epub ahead of print: [please include Day Month Year]. doi:10.1136/ emermed-2020-209470
An estimated five million people die from injuries every year, disproportionately affecting low-income and middle-income countries (LMICs). ${ }^{1}$ It is estimated that a reduction in the trauma mortality rate of LMICs to that of high-income countries would prevent approximately two million deaths annually. ${ }^{23}$ Violence and conflict make up an increasing proportion of the global burden of injury. ${ }^{4}$ Globally, more than 1 in 10 violent deaths occur in conflict settings. ${ }^{5}$

\section{Key messages}

What is already known on this subject

- During 2015 approximately 18300 patients sought help at the Médecins Sans Frontières trauma centre in Kunduz (Kunduz Trauma Centre (KTC)). To help prioritise treatment KTC used the South African Triage Scale. To date, there are few studies that assess how triage levels correspond with outcome in low-resource conflict settings.

\section{What this study adds}

- Our study suggests that triage levels had high sensitivity to predict outcome. Delay in arrival and low mortality indicate that prehospital management is key in this setting to increase trauma survivability.

In Afghanistan, a low-income country affected by war and political violence for more than 35 years, conflict-related trauma is a significant health problem. ${ }^{67}$ The country is among the top five countries in the world affected by violent deaths due to conflict, killing nearly 15000 people annually and accounting for $5.9 \%$ of all annual deaths. ${ }^{8}$ The northern province of Kunduz is a region particularly affected by conflict. ${ }^{5-10}$ In order to meet trauma care needs Médecins Sans Frontières (MSF) opened Kunduz Trauma Centre (KTC) in 2011. This facility was operational until 3 October 2015, when a US airstrike hit and destroyed the facility, killing 14 MSF staff, 24 patients and 4 caretakers. ${ }^{10}$

Care at dedicated trauma centres reduces trauma-related mortality by $9 \%-25 \%$ compared with non-trauma centres. ${ }^{11}$ A central mechanism of trauma care is to triage patients in order to prioritise resources and ensure fast identification of potentially fatal conditions of those arriving to the hospital ED. ${ }^{12}$ MSF uses standardised ED packages to triage and provide appropriate initial care to trauma patients at its trauma facilities. ${ }^{13}$ The South African Triage Scale (SATS) is the main triage system that is used in the MSF ED packages. While numerous studies evaluate triage systems, few assess how triage levels correspond to outcomes in lowresource armed conflict settings. This study therefore aims to assess to what extent SATS triage levels 


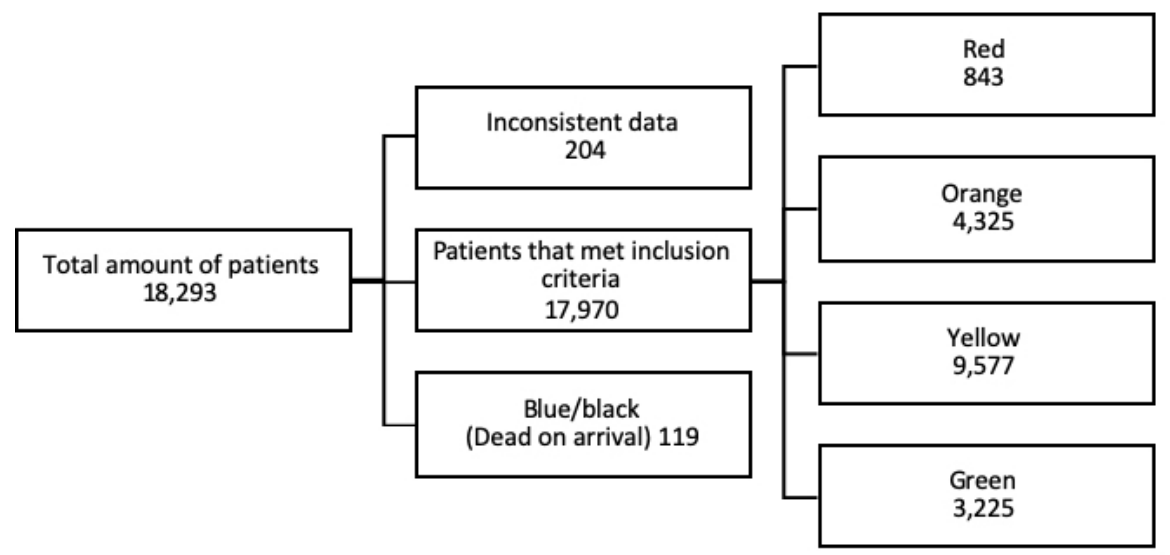

Figure 1 Study sample. Patients admitted to Kunduz Trauma Centre (KTC) January-September 2015.

correlated to outcomes in terms of hospital admission, intensive care unit (ICU) admission and mortality for patients treated at KTC.

\section{MATERIALS AND METHODS}

KTC was located in Kunduz city, the fifth largest city in Afghanistan situated in Kunduz province, with an estimated population of one million. ${ }^{14}$ Before the opening of KTC, patients had to travel to Kabul, approximately $340 \mathrm{~km}$ by road, or to Pakistan, for trauma care. During its functional years, the trauma centre offered free around-the-clock care, performed more than 15000 surgeries and treated more than 68000 emergency patients with a staff of 460 employees. ${ }^{10}$

This study included all patients registered at the ED at KTC from 1 January 2015 to 18 September 2015. The study period was chosen as data from other years was inconclusive and did not provide variables of sufficient quality for this study. This study included all 18293 patients that were registered at the ED during the study period. Out of these, 323 patients were excluded due to inconsistent data in key variables and due to being registered as dead on arrival (figure 1).

The data used in this study were routinely collected using a standardised data collection form used across all MSF missions. Data were recorded in a logbook and then transferred into an electronic database (Microsoft Excel). The database was transmitted to the MSF headquarters in Brussels where it was reviewed for accuracy. Discrepancies were addressed and corrected after contact with programme personnel involved in data entry.

SATS was the triage system used during normal activities at KTC. It is based on physiological parameters and a list of clinical discriminators. Each of the five triage levels provide time-totreatment targets; red (immediately), orange (less than $10 \mathrm{~min}$ ), yellow (less than 1 hour), green (less than 4 hours) and blue (dead on arrival) (online supplemental figure 1). The MSF ED package also includes the Simple Triage and Rapid Treatment triage system which was used in case of multiple casualty incidents. It assesses the ability to walk, spontaneous breathing, respiratory rate, perfusion and level of consciousness. ${ }^{15}$ The majority of patients at KTC were triaged using SATS as this was the system used during normal activities at the ED. Hence our study only assessed SATS. The data set used includes variables to ascertain which system was used for a given patient but is not consistently recorded.
Hospital admission, ICU admission and mortality were chosen as outcomes, serving as proxy measures for injury severity. Patients admitted to the ICU were a subgroup of those admitted to hospital. The explanatory variable was triage level. Covariates including age, sex and delay to arrival were used to characterise the study sample and to adjust the association between triage levels and outcome.

Statistical analysis was performed using R V.3.3.2. (The R Foundation, R Core Team, 1020 Vienna, Austria). Descriptive statistics are reported as count and percentage, mean and SD or median and IQR as applicable. First an unadjusted analysis using logistic regression was conducted for each outcome. In terms of ICU admission and mortality the analysis only included patients triaged as red or orange. Second, an adjusted analysis using logistic regression that included the covariates sex, age and delay to arrival in addition to triage level was conducted. We conducted the adjusted analysis to account for factors not included in the triage systems. We used 95\% CIs and a significance level of $5 \%$.

\section{Patient and public involvement}

Patients were not informed about this specific study since it is a retrospective study and KTC could provide no follow-up. Therefore, patient and public involvement were not applicable.

\section{RESULTS}

Data were captured on a total of 18293 patients out of which 323 were excluded. Thus, a total of 17970 patients were included in the final analysis. Out of all patients $843(4.7 \%)$ were triaged as red, $4325(24 \%)$ as orange, $9577(53.3 \%)$ as yellow and 3225 (17.9\%) as green (figure 1).

Out of all patients included $76.4 \%$ were men (table 1 ). The mean patient age was 23.1 (SD 16.8 ) years and $61.9 \%$ of patients were under 25 years of age. Patients categorised as red had a higher mean age (25.1, SD 15.8) while age was lower in all other triage categories $(\mathrm{p}<0.001)$.

A total of $3677(20.5 \%)$ patients admitted to the ED were hospitalised, the majority of whom were triaged as either orange $(1,856)$ or yellow $(1,029)$. Out of all the patients admitted to hospital $273(1.5 \%)$ patients were admitted to ICU, 97.8\% of whom were triaged as red or orange. Altogether $25.6 \%$ of all red patients were admitted to the ICU. A total of $100(0.6 \%)$ patients died, $90 \%$ of whom were triaged as red, the remaining 
Table 1 Patient characteristics for patients admitted at the Kunduz Trauma Centre January-September 2015

\begin{tabular}{|c|c|c|c|c|c|}
\hline & Red & Orange & Yellow & Green & Total \\
\hline Total & 843 & 4325 & 9577 & 3225 & 17970 \\
\hline Male (\%) & $719(85.3)$ & $3524(81.5)$ & $7134(74.5)$ & $2351(72.9)$ & $13728(76.4)$ \\
\hline \multicolumn{6}{|l|}{ Age category, years (\%) } \\
\hline$<5$ & $42(5.0)$ & $392(9.1)$ & $1133(11.8)$ & $209(6.5)$ & $1776(9.9)$ \\
\hline $5-9$ & $83(9.8)$ & $506(11.7)$ & $1270(13.3)$ & $163(5.1)$ & $2022(11.3)$ \\
\hline $10-14$ & $103(12.2)$ & $551(12.7)$ & $1552(16.2)$ & $352(10.9)$ & $2558(14.2)$ \\
\hline $15-19$ & $102(12.1)$ & $488(11.3)$ & $1304(13.6)$ & $632(19.6)$ & $2526(14.1)$ \\
\hline $20-24$ & $117(13.9)$ & $576(13.3)$ & $1009(10.5)$ & $520(16.1)$ & $2222(12.4)$ \\
\hline $25-29$ & $102(12.1)$ & $459(10.6)$ & 725 (7.6) & $349(10.8)$ & $1635(9.1)$ \\
\hline $30-34$ & $77(9.1)$ & $291(6.7)$ & $506(5.3)$ & $233(7.2)$ & $1107(6.2)$ \\
\hline $35-39$ & $71(8.4)$ & $254(5.9)$ & $428(4.5)$ & $185(5.7)$ & $938(5.2)$ \\
\hline $40-44$ & $37(4.4)$ & $217(5.0)$ & $378(3.9)$ & $162(5.0)$ & $794(4.4)$ \\
\hline $45-49$ & $30(3.6)$ & $143(3.3)$ & $300(3.1)$ & $116(3.6)$ & $589(3.3)$ \\
\hline $50-54$ & $23(2.7)$ & $143(3.3)$ & $337(3.5)$ & $122(3.8)$ & $625(3.5)$ \\
\hline $55-59$ & $17(2.0)$ & $63(1.5)$ & $145(1.5)$ & $52(1.6)$ & $277(1.5)$ \\
\hline $60-64$ & $21(2.5)$ & $115(2.7)$ & $219(2.3)$ & $72(2.2)$ & $427(2.4)$ \\
\hline $65-69$ & $4(0.5)$ & $40(0.9)$ & $86(0.9)$ & $15(0.5)$ & $145(0.8)$ \\
\hline $70-74$ & $8(0.9)$ & $56(1.3)$ & $100(1.0)$ & $32(1.0)$ & $196(1.1)$ \\
\hline $75-79$ & $2(0.2)$ & $11(0.3)$ & $31(0.3)$ & $3(0.1)$ & $47(0.3)$ \\
\hline $80-84$ & $0(0.0)$ & $9(0.2)$ & $35(0.4)$ & $5(0.2)$ & $49(0.3)$ \\
\hline $85+$ & $4(0.5)$ & $11(0.3)$ & $19(0.2)$ & $3(0.1)$ & $37(0.2)$ \\
\hline Mean age (SD) & $25.13(15.77)$ & $23.92(16.98)$ & $21.94(17.24)$ & $24.90(15.15)$ & $23.10(16.80)$ \\
\hline Multiple injuries (\%) & $269(31.9)$ & $567(13.1)$ & 247 (2.6) & $39(1.2)$ & $1122(6.2)$ \\
\hline \multicolumn{6}{|l|}{ Delay to arrival (\%) } \\
\hline$\leq 1$ hour & $348(41.3)$ & $1431(33.1)$ & $2149(22.4)$ & $398(12.3)$ & $4326(24.1)$ \\
\hline$\leq 6$ hours & $299(35.5)$ & $1095(25.3)$ & $1131(11.8)$ & $204(6.3)$ & $2729(15.2)$ \\
\hline$\leq 1$ day & $161(19.1)$ & $1332(30.8)$ & $4258(44.5)$ & $1430(44.3)$ & $7181(40.0)$ \\
\hline$>1$ day & $35(4.2)$ & $467(10.8)$ & $2039(21.3)$ & $1193(37.0)$ & $3734(20.8)$ \\
\hline \multicolumn{6}{|l|}{ Nature of injury (\%) } \\
\hline Burn & $2(0.2)$ & $46(1.1)$ & $81(0.8)$ & $13(0.4)$ & $142(0.8)$ \\
\hline Contusion or superficial & $26(3.1)$ & $771(17.8)$ & $3646(38.1)$ & $2037(63.2)$ & $6480(36.1)$ \\
\hline Dislocation & $0(0.0)$ & $41(0.9)$ & $49(0.5)$ & $4(0.1)$ & $94(0.5)$ \\
\hline Fracture & $338(40.1)$ & $1930(44.6)$ & $3841(40.1)$ & $439(13.6)$ & $6548(36.4)$ \\
\hline Internal organ injury & $191(22.7)$ & $129(3.0)$ & $47(0.5)$ & $20(0.6)$ & $387(2.2)$ \\
\hline Open wound & $158(18.7)$ & $648(15.0)$ & $676(7.1)$ & $125(3.9)$ & $1607(8.9)$ \\
\hline Others non-trauma & $6(0.7)$ & $47(1.1)$ & $137(1.4)$ & $73(2.3)$ & $263(1.5)$ \\
\hline Others trauma related & $119(14.1)$ & $691(16.0)$ & $1002(10.5)$ & $477(14.8)$ & $2289(12.7)$ \\
\hline Sprains and strains & $0(0.0)$ & $14(0.3)$ & $59(0.6)$ & $29(0.9)$ & $102(0.6)$ \\
\hline Unclassified & $3(0.4)$ & $8(0.2)$ & $39(0.4)$ & $8(0.2)$ & $58(0.3)$ \\
\hline Self-referred (\%) & $835(99.1)$ & $4323(100.0)$ & $9577(100.0)$ & $3225(100.0)$ & $17960(99.9)$ \\
\hline Admission (\%) & $708(84.0)$ & $1856(42.9)$ & $1029(10.7)$ & $84(2.6)$ & $3677(20.5)$ \\
\hline Intensive care unit mission (\%) & $216(25.6)$ & $51(1.2)$ & $6(0.1)$ & $0(0.0)$ & $273(1.5)$ \\
\hline Died (\%) & $90(10.7)$ & $10(0.2)$ & $0(0.0)$ & $0(0.0)$ & $100(0.6)$ \\
\hline
\end{tabular}

10 as orange. The most common site for injury for all triage levels was the extremities, affecting $84 \%$ of patients.

The risk of hospital admission increased with each triage level (table 2).

Both early ( $\leq 6$ hours) and delayed arrival ( $>1$ day) showed an increased risk for hospital admission (table 3 ).

Table 2 Associations of triage levels with hospital admission

\begin{tabular}{lllll}
\hline & OR & $95 \% \mathrm{Cl}$ lower bound & $\begin{array}{l}95 \% \mathrm{Cl} \text { upper } \\
\text { bound }\end{array}$ & P value \\
\hline $\begin{array}{l}\text { Red } \\
\text { (reference) }\end{array}$ & 1 & & & \\
Orange & 0.143 & 0.118 & 0.173 & $<0.05$ \\
Yellow & 0.023 & 0.019 & 0.028 & $<0.05$ \\
Green & 0.005 & 0.004 & 0.007 & $<0.05$ \\
\hline
\end{tabular}

Both the risk of ICU admission and death increased for red triage levels in comparison to orange triage levels (tables 4 and 5). For ICU admission red triage level had a significantly higher risk.

Early arrival ( $\leq 6$ hours) showed an increased risk for ICU admission in the orange and red triage levels (table 6).

Neither gender, age nor delay to arrival showed any significant effect on mortality for red and orange triage level patients (table 7).

\section{DISCUSSION}

This study confirmed a negative correlation between SATS triage levels and hospital admission, ICU admission and in-hospital death. Hospital admission increased with every triage level and red patients had a considerably higher risk of ICU admission in comparison to orange patients. Likewise, red patients had a 


\begin{tabular}{|c|c|c|c|c|}
\hline & OR & $\begin{array}{l}95 \% \mathrm{Cl} \text { lower } \\
\text { bound }\end{array}$ & $\begin{array}{l}95 \% \mathrm{Cl} \text { upper } \\
\text { bound }\end{array}$ & $P$ value \\
\hline $\begin{array}{l}\text { Red } \\
\text { (reference) }\end{array}$ & 1 & & & \\
\hline Orange & 0.141 & 0.116 & 0.171 & $<0.05$ \\
\hline Yellow & 0.023 & 0.019 & 0.028 & $<0.05$ \\
\hline Green & 0.005 & 0.003 & 0.006 & $<0.05$ \\
\hline Male gender & 1.187 & 1.069 & 1.320 & $<0.05$ \\
\hline Age & 1.006 & 1.003 & 1.008 & $<0.05$ \\
\hline $\begin{array}{l}\text { Delay to arrival } \leq 1 \text { hour } \\
\text { (reference) }\end{array}$ & 1 & & & \\
\hline$\leq 6$ hours & 2.167 & 1.914 & 2.454 & $<0.05$ \\
\hline$>6$ hours to $\leq 24$ hours & 1.032 & 0.920 & 1.157 & 0.593 \\
\hline$>1$ day & 2.021 & 1.768 & 2.310 & $<0.05$ \\
\hline
\end{tabular}

significantly higher risk of mortality. Our results suggest triage levels applied at the KTC had high sensitivity to predict severity outcome for high-risk trauma patients in this context. This is one of few studies to study the associations between triage level and outcomes in a low-resource conflict setting.

Similar results have been shown by Dalwai et $a l^{16}$ showing the validity of SATS at KTC having mortality and hospital admission as outcomes. It concluded that SATS can determine the accuracy of triage levels applied to the most vulnerable and ill patients. Our study considers ICU admission as a severity outcome, thus further indicating the validity of the use of SATS at KTC. The validity and reliability of a triage scale can be calculated using different means. SATS has been validated by the comparison of different triage-level outcomes depending on who performs the triage. ${ }^{17}$ It is also possible to validate the triage scale by comparing it to another validated triage scale or by evaluating each triage level to predicting outcome. Farrokhnia et al have researched the validity and reliability of multiple ED triage scales. ${ }^{18}$ They found that most triage scales had insufficient reliability in comparison to each other or to a gold standard. The study also revealed a lack of validity in predicting hospital mortality and admission. None of the studies included in the systematic review adjusted mortality rate to age and gender. In our study we have chosen to study the association between triage level and outcome. Although the data limited the possibility to evaluate the triage level to a gold standard, our methods could still estimate the reliability and validity of the triage levels.

Although it is not surprising that SATS as a triage scale could predict negative outcome, it is interesting to find that similar results were shown even after results were adjusted to covariates. In our study only $84(2.6 \%)$ patients triaged as green were hospitalised, none of whom were admitted to the ICU or died, which indicates high specificity. However, both early ( $\leq 6$ hours) and delayed arrival ( $>1$ day) showed an increased risk for hospital admission in all triage levels while early arrival ( $\leq 6$ hours) showed an increased risk for ICU admission in orange and red

\begin{tabular}{|c|c|c|c|c|}
\hline & $\mathrm{OR}$ & $\begin{array}{l}95 \% \mathrm{Cl} \text { lower } \\
\text { bound }\end{array}$ & $\begin{array}{l}95 \% \mathrm{Cl} \text { upper } \\
\text { bound }\end{array}$ & $P$ value \\
\hline $\begin{array}{l}\text { Red } \\
\text { (reference) }\end{array}$ & 1 & & & \\
\hline Orange & 0.035 & 0.025 & 0.047 & $<0.05$ \\
\hline
\end{tabular}

Table 5 Associations of triage levels with mortality

\begin{tabular}{lllll}
\hline & OR & $95 \% \mathrm{Cl}$ lower bound & $\begin{array}{c}95 \% \mathrm{Cl} \text { upper } \\
\text { bound }\end{array}$ & P value \\
\hline Red & 1 & & & \\
Orange & 0.019 & 0.009 & 0.036 & $<0.05$ \\
\hline
\end{tabular}

triage levels. These results indicate that delay correlates to the risk of negative outcome.

Only 100 patients died in the ED, corresponding to a mortality rate of $0.6 \%$, while $2.7 \%$ of hospitalised patients died. This is a considerably lower mortality compared with trauma centres in USA that report rates around $8 \% .{ }^{11}$ Four public hospitals in Mumbai, Kolkata and New Delhi in India, had a mortality rate of $7.3 \%$ within the first 24 hours. ${ }^{19}$ This suggests that the mortality rate of KTC was remarkably low, which may imply that the most critically ill patients did not reach the hospital in time for care due to gaps in prehospital care capacity and capability. This was suggested as a reason for similarly low hospital mortality rates in a study from Iraq during the Mosul offensive. ${ }^{20} 21$

A key factor to reduce mortality is early hospital care. Our study shows that almost all patients (99.9\%) were self-referred to the hospital, which not only causes delay in treatment but indicates yet again that the most critically ill patients most likely never reached the trauma facility. This inevitably increases the prehospital mortality rate. An American study conducted on US troops deployed to Iraq and Afghanistan showed that approximately $85 \%$ of prehospital deaths were due to haemorrhage, which indicates that early arrival is key for survival and that a high proportion of trauma deaths may be preventable with rapid transport to hospital. ${ }^{22}$ A study conducted by Guzmán et al shows that $25.5 \%$ of trauma patients arrived with a $>24$ hours delay at KTC during 2013-2015, indicating the need of increased access to prehospital care and transport in the area. ${ }^{23}$ In our study, only $7055(39.3 \%)$ of patients reached care within 6 hours, and a fourth of patients within 1 hour, although, the patients triaged as red had the least delay. Delay is an obstacle to the paradigm of early and fast treatment of patients and should be minimised to further improve survivability. 2224

Targeted public health action to strengthen implementation of triage systems and well-organised emergency care improve trauma survivability and are all a part of a resolution from the WHO's seventy-second World Health Assembly on Emergency and Trauma care (WHA72/31). Our study, as well as a study by Hemat et al concludes that KTC saved many lives and that the majority of patients at KTC were successfully treated. ${ }^{25}$ It is estimated that more than 154250 disability-adjusted life years were averted at KTC. ${ }^{26}$ The study also concludes that there was

\begin{tabular}{|c|c|c|c|c|}
\hline & OR & $\begin{array}{l}95 \% \mathrm{Cl} \text { lower } \\
\text { bound }\end{array}$ & $\begin{array}{l}95 \% \mathrm{Cl} \text { upper } \\
\text { bound }\end{array}$ & $P$ value \\
\hline $\begin{array}{l}\text { Red } \\
\text { (reference) }\end{array}$ & 1 & & & \\
\hline Orange & 0.032 & 0.023 & 0.044 & $<0.05$ \\
\hline Male gender & 1.100 & 0.757 & 1.630 & 0.624 \\
\hline Age & 0.975 & 0.965 & 0.985 & $<0.05$ \\
\hline $\begin{array}{l}\text { Delay to arrival } \leq 1 \text { hour } \\
\text { (reference) }\end{array}$ & 1 & & & \\
\hline$\leq 6$ hours & 1.882 & 1.361 & 2.613 & $<0.05$ \\
\hline$>6$ hours to $\leq 24$ hours & 1.462 & 0.999 & 2.134 & 0.049 \\
\hline$>1$ day & 1.544 & 0.809 & 2.793 & 0.167 \\
\hline
\end{tabular}

Daebes HL, et al. Emerg Med J 2021;0:1-6. doi:10.1136/emermed-2020-209470 
Table 7 Adjusted associations of triage levels with mortality

\begin{tabular}{llllc}
\hline & OR & $\begin{array}{l}95 \% \mathrm{Cl} \text { lower } \\
\text { bound }\end{array}$ & $\begin{array}{l}95 \% \mathrm{Cl} \text { upper } \\
\text { bound }\end{array}$ & P value \\
\hline $\begin{array}{l}\text { Red } \\
\text { (reference) }\end{array}$ & 1 & & & \\
Orange & 0.019 & 0.009 & 0.036 & $<0.05$ \\
\hline Male gender & 1.243 & 0.685 & 2.453 & 0.500 \\
\hline Age & 1.019 & 1.006 & 1.031 & $<0.05$ \\
$\begin{array}{l}\text { Delay to arrival } \leq 1 \text { hour } \\
\text { (reference) }\end{array}$ & 1 & & & \\
\hline$\leq 6$ hours & 1.044 & 0.639 & 1.697 & 0.863 \\
$>6$ hours to $\leq 24$ hours & 1.134 & 0.641 & 1.961 & 0.659 \\
\hline 1 day & 1.011 & 0.333 & 2.512 & 0.982 \\
\hline
\end{tabular}

a strong need of implementation of prehospital care. Follow-up studies on long-term disability for patients in correlation to their initial triaging could give a wider perspective regarding the importance of correctly applied triage levels and possibly also a wider knowledge on which aspects to take into consideration while triaging.

\section{Limitations}

The broad inclusion criteria might have had a negative impact on the significance of the results, yet it was considered necessary to maintain a heterogeneous population for the results to be representative. The US bombing of the KTC and the subsequent destruction of medical records limited the patient follow-up.

\section{CONCLUSION}

This study confirmed a negative correlation between SATS triage level and hospital admission, ICU-admission and in-hospital death. Our results suggest triage levels applied at the KTC had high sensitivity to predict severity outcome for high-risk trauma patients. Our results indicate that delay in arrival had an impact on triage levels. Further, the low mortality found at KTC indicates that many critically injured trauma patients in Kunduz may not have survived long enough to reach care. Therefore, in this setting, targeted efforts to improve prehospital management and transport is likely to improve both triage level outcomes and have a positive impact on trauma survivability.

Correction notice This article has been corrected since it was published. In the Results section of the Abstract $28.7 \%$ were triaged as red or orange instead of $70 \%$.

Acknowledgements The authors thank the brave staff that under difficult security situations courageously worked at the Trauma Centre in Kunduz. The authors especially think of the 42 staff and patients that lost their lives following the airstrike on 3 October 2015.

Contributors All the authors have at some point read and revised the article. Coauthors from MSF Afghanistan have additionally been crucial in collecting all data and information. Data were analysed mainly by MGW, LLT and HLD. JvS revised the paper and supervised the entire work with the help of MT, MNe and MGW. JvS acted as the guarantor of the article.

Funding MGW, MNe and JvS were funded by a research grant (K919532243) from the National Board of Health and Welfare in Sweden.

\section{Competing interests None declared.}

\section{Patient consent for publication Not applicable.}

Ethics approval Studies conducted in resources scarce, complex conflict environments include several ethical considerations. We are convinced that research can shed light on the problems the populations are exposed to. But careful ethical considerations are needed. This study was retrospective and did not affect the treatment of any patient. Personal data were anonymous to those conducting the analysis. The specific group studied did not gain from this study, but increased knowledge of trauma care in conflicts is crucial to adapt and improve care. This research fulfilled the exemption criteria set by the Médecins Sans Frontières Ethics Review Board for a posteriori analysis of routinely collected clinical data and thus did not require MSF ERB review. It was conducted with permission from Medical Director, Operational Centre Brussels, Médecins Sans Frontières. This research also got the approval of the Afghani Institutional Review Board of the Ministry of Public Health (ref: 444796)

Provenance and peer review Not commissioned; externally peer reviewed.

Data availability statement Data are available upon reasonable request. Data may be obtained from a third party and are not publicly available.

Supplemental material This content has been supplied by the author(s). It has not been vetted by BMJ Publishing Group Limited (BMJ) and may not have been peer-reviewed. Any opinions or recommendations discussed are solely those of the author(s) and are not endorsed by BMJ. BMJ disclaims all liability and responsibility arising from any reliance placed on the content. Where the content includes any translated material, BMJ does not warrant the accuracy and reliability of the translations (including but not limited to local regulations, clinical guidelines, terminology, drug names and drug dosages), and is not responsible for any error and/or omissions arising from translation and adaptation or otherwise.

Open access This is an open access article distributed in accordance with the Creative Commons Attribution Non Commercial (CC BY-NC 4.0) license, which permits others to distribute, remix, adapt, build upon this work non-commercially, and license their derivative works on different terms, provided the original work is properly cited, appropriate credit is given, any changes made indicated, and the use is non-commercial. See: http://creativecommons.org/licenses/by-nc/4.0/.

\section{ORCID iDs}

Hadjer Latif Daebes http://orcid.org/0000-0002-3246-4112

Martin Gerdin Wärnberg http://orcid.org/0000-0001-6069-4794

\section{REFERENCES}

1 Norton R, Kobusingye O. Injuries. N Engl J Med Overseas Ed 2013;368:1723-30.

2 Mock C, Joshipura M, Arreola-Risa C, et al. An estimate of the number of lives that could be saved through improvements in trauma care globally. World I Surg 2012;36:959-63.

3 Kotagal M, Agarwal-Harding KJ, Mock C, et al. Health and economic benefits of improved injury prevention and trauma care worldwide. PLoS One 2014;9:e91862.

4 GBD 2015 DALYs and HALE Collaborators. Global, regional, and national disabilityadjusted life-years (DALYs) for 315 diseases and injuries and healthy life expectancy (HALE), 1990-2015: a systematic analysis for the global burden of disease study 2015. Lancet 2016;388:1603-58.

5 Alvazzi del Frate A, Krause K, Nowak M. Every body counts: Launch of the global burden of armed violence 2015, 2016. The Geneva Declaration. Available: http:// www.genevadeclaration.org/measurability/global-burden-of-armed-violence/globalburden-of-armed-violence-2015.html

6 The World Bank. World bank country and lending groups, 2017. Available: https:// datahelpdesk.worldbank.org/knowledgebase/articles/906519-world-bank-countryand-lending-groups

7 Bank W. Afghanistan builds capacity to meet healthcare challenges.: the world bank, 2017. Available: http://www.worldbank.org/en/news/feature/2015/12/22/ afghanistan-builds-capacity-meet-healthcare-challenges

8 OCHA. About OCHA Afghanistan.: United nations office for the coordination of humanitarian Affairs, 2017. Available: http://www.unocha.org/afghanistan/aboutocha-afghanistan

9 Kassebaum NJ, Arora M, Barber RM, et al. Global, regional, and national disabilityadjusted life-years (DALYs) for 315 diseases and injuries and healthy life expectancy (HALE), 1990-2015: a systematic analysis for the global burden of disease study 2015. Lancet 2016;388:1603-58.

10 MSF. Initial MSF internal review: attack on Kunduz trauma centre: Afghanistan.: Médecins sans Frontières, 2015. Available: http://kunduz.msf.org/pdf/20151030_ kunduz_review_EN.pdf

11 MacKenzie EJ, Rivara FP, Jurkovich GJ, et al. A national evaluation of the effect of trauma-center care on mortality. N Engl J Med 2006;354:366-78.

12 Champion HR, Copes WS, Sacco WJ, et al. The major trauma outcome study: establishing national norms for trauma care. J Trauma 1990;30:1356-65

13 Valles P, Van den Bergh R, van den Boogaard W, et al. Emergency department care for trauma patients in settings of active conflict versus urban violence: all of the same calibre? Int Health 2016;8:390-7.

14 UN-HABITAT. State of Afghan cities: Un-habitat, 2015. Available: https://unhabitat. org/books/soac2015/

15 Twomey M. The South African triage scale (SATS): training manual 2012. Health WCDo, 2012.

16 Dalwai MK, Twomey M, Maikere J, et al. Reliability and accuracy of the South African triage scale when used by nurses in the emergency department of Timergara Hospital, Pakistan. S Afr Med J 2014;104:372-7.

17 Gottschalk SB, Wood D, DeVries S, et al. The Cape triage score: a new triage system South Africa. proposal from the Cape triage group. Emerg Med J 2006;23:149-53. 


\section{Original research}

18 Farrokhnia N, Göransson KE. Swedish emergency department triage and interventions for improved patient flows: a national update. Scand J Trauma Resusc Emerg Med 2011;19:72.

19 Gerdin M, Roy N, Khajanchi M, et al. Validation of a novel prediction model for early mortality in adult trauma patients in three public university hospitals in urban India. BMC Emerg Med 2016;16:15.

20 Nerlander MP, Haweizy RM, Wahab MA, et al. Epidemiology of trauma patients from the Mosul offensive, 2016-2017: results from a dedicated trauma center in Erbil, Iraqi Kurdistan. World J Surg 2019;43:368-73.

21 Tounsi LL, Daebes HL, Gerdin Wärnberg M, et al. Association between gender, surgery and mortality for patients treated at Médecins sans Frontières trauma centre in Kunduz, Afghanistan. World J Surg 2019;43:2123-30.
22 Kelly JF, Ritenour AE, McLaughlin DF, et al. Injury severity and causes of death from operation Iraqi freedom and operation enduring freedom: 2003-2004 versus 2006. Journal of Trauma and Acute Care Surgery 2008;64:S21-7.

23 Beltrán Guzmán I, Gil Cuesta J, Trelles M, et al. Delays in arrival and treatment in emergency departments: women, children and non-trauma consultations the most at risk in humanitarian settings. PLoS One 2019;14:e0213362.

24 Eastridge BJ, Mabry RL, Seguin P, et al. Death on the battlefield (2001-2011): implications for the future of combat casualty care. Journal of trauma and acute care surgery 2012;73:S431-7.

25 Hemat $\mathrm{H}$, Shah $\mathrm{S}$, Isaakidis $\mathrm{P}$, et al. Before the bombing: high burden of traumatic injuries in Kunduz trauma center, Kunduz, Afghanistan. PLoS One 2017;12:e0165270.

26 Trelles M, Stewart BT, Hemat H, et al. Averted health burden over 4 years at Médecins Sans Frontières (MSF) Trauma Centre in Kunduz, Afghanistan, prior to its closure in 2015. Surgery 2016;160:1414-21. 